\title{
Comparative Study of Growth Statistics of Two Species of Paulownia and Optimization of Rooting Methods
}

\author{
Hari Krishna Saiju*, Abhishesh Bajracharya, Brishav Rajbahak, Stuti Ghimire
}

Department of Biotechnology, Asian Institute of Technology and Management (AITM) Lalitpur, Nepal

\begin{abstract}
Paulownia is a fast-growing woody tree, native to the forests of China. It belongs to the family Scrophulariaceae and is mainly used as a source of wood for furniture and musical instruments. Due to its fast-growing nature and high-quality of wood, there has been growing interest in cultivation and research of Paulownia in Nepal. Growth comparison was performed by measuring shoot length in in vitro condition. Among two species of Paulownia - Paulownia tomentosa (Thunb.) Steud and Paulownia fortuneii (Seem.) Hemsl., the growth rate of P. tomentosa was found to be 0.355 $\mathrm{cm} /$ week while that of $P$. fortuneii was found to be $0.637 \mathrm{~cm} /$ week in in-vitro conditions in MS medium supplemented with $0.1 \mathrm{mg} / 1 \mathrm{NAA}$ and $1 \mathrm{mg} / 1 \mathrm{BAP}$. Optimization of rooting methods was also performed, in which, sand rooting was found to be easier and more effective than in-vitro rooting. Dipping the plantlets in $1 \mathrm{mg} / 1$ of NAA was found to produce longer and denser roots than lower or higher concentrations during sand rooting.
\end{abstract}

Keywords: Paulownia tomentosa, Paulownia fortuneii, growth comparison, in-vitro rooting, sandrooting, nodal culture

*Corresponding Author

Email: hk.saiju@aitm.edu.np

\section{Introduction}

Paulownia is a fast-growing, woody tree native to the forests of China [1]. It is a deciduous tree but becomes evergreen in the tropics [2]. It belongs to the family Scrophulariaceae and is majorly used as a source of wood for furniture and musical instruments [3]. It has a very low thermal conductivity making it ideal for construction of insulative structures [4]. Each tree can produce 44 cubic feet of wood in average and can be harvested after 8-10 years of plantation. It is also tolerant to pollutants and can grow in many types of soils. Its leaves and flowers show medicinal properties and can also be used as fodder and fertilizers due to their high nitrogen concentration [5]. Its tolerance to drought and soil extremes makes it commercially important for use in the reclamation of surfacemined land [6]. It is also a suitable raw material for pyrolysis conversion into liquid and gaseous products [7]. The generic name, Paulownia, honors Anna Pavlovna of Russia [8].

Paulownia tomentosa was first introduced in Nepal in 1988 AD by International Centre for Integrated Mountain Development (ICIMOD) in Godavari. It was normally propagated through seeds but due to seed dormancy and slow seedling growth, tissue culture products have been used. Among the several species of Paulownia, Paulownia tomentosa (Thunberg) Steudel and Paulownia fortuneii (Seemann) Hemsley are the most widely used species in the context of Nepal. The former is usually found below an altitude of $1800 \mathrm{~m}$ while the latter is usually found below an altitude of $2000 \mathrm{~m}$ $[1,9]$.

Due to the booming market for Paulownia plants in Nepal, the plantlets have to be manufactured in huge amounts which can be performed by tissue culture. But there have been no publications of research about the in-vitro growth statistics and very few data regarding lab-to-land techniques like acclimatization and rooting methods. In this study, we aim to compare the in-vitro growth statistics of the two species to shed light on their growth patterns. Furthermore, we have extrapolated the type and concentrations of hormones and the method of rooting required for optimal root initiation.

\section{Materials and Methods Sample and Material Collection}

Two different species of Paulownia, namely, Paulownia tomentosa and Paulownia fortuneii were used in this experiment. Paulownia fortuneii samples were brought in sterile culture jars from the Department of Plant Resources (DPR), Thapathali. 
Paulownia tomentosa samples available in the Plant Tissue Culture laboratory, Himalayan White House International College, Khumaltar were used for the project.

\section{Multiplication}

Due to the requirement of a high number of plants, the samples were mass propagated in MS medium supplemented with hormone concentrations of 0.1 mg/l Naphthalene Acetic Acid (NAA manufactured by Sigma Chemical Co.) and $1 \mathrm{mg} / 1$ Benzyl Amino Purine (BAP - manufactured by S.D. Fine-Chem Limited) in $150 \mathrm{ml}$ culture vessels. The growth medium and culture equipment were autoclaved (manufactured by Life Steriware) at $121^{\circ} \mathrm{C}$ temperature and $15 \mathrm{lb}$./sq. inch pressure and nodal culture of the samples was performed in a Laminar Air Flow Hood (manufactured by Amar Chand \& Company (ACCO). As a result, we performed subcultures twice and prepared a total of 30 vessels for each sample, with an average of 5 explants per vessel, which were stored in an incubation room, under fluorescent tube-lights (2000 lux) at a constant temperature of $25^{\circ} \mathrm{C}$ [1].

\section{Shoot Growth Comparison}

After two subsequent subcultures, we met the required explant number which was estimated to be 250 explants. Following this, nodal cultures were performed using MS medium with $0.1 \mathrm{mg} / 1$ NAA and $1 \mathrm{mg} / 1 \mathrm{BAP}$, with only one explant per vessel, for ease of measurement. 20 vessels were produced for each plant species, which were also stored in the incubation room, under 2000 lux fluorescent tube lights at $25^{\circ} \mathrm{C}$ temperature. Culture vessels were recorded alongside a scale every week for 7 consecutive weeks [1].

\section{Rooting Optimization \\ Sand Rooting}

In this experiment, a total of 30 culture vessels were removed from the incubation room and exposed to indirect sunlight at room temperature for 10 days for acclimatization process. Nodal cuttings of the invitro plants, including at least one leaf, were prepared and placed into solutions of differing concentrations of NAA $(0.5 \mathrm{mg} / \mathrm{l}, 1 \mathrm{mg} / 1$ and 1.5 $\mathrm{mg} / \mathrm{l})$ for about 10 minutes. The cuttings were then transplanted into rooting trays packed with autoclave-sterilized wet sand and placed into a polythene chamber. After a week of incubation (with water spraying twice a day) at room temperature, liquid MS media was added to the sand twice a week. The plantlets were removed from the sand after 4 weeks of incubation, for the measurement of root density and length [10-12]

\section{In-vitro Rooting}

In this experiment, a total of 30 plantlets from culture vessels were transferred into MS media with differing NAA concentrations $(0.5 \mathrm{mg} / \mathrm{l}, 1$ $\mathrm{mg} / \mathrm{l}$, and $1.5 \mathrm{mg} / \mathrm{l})$. These vessels were stored in the incubation room under 2000 lux fluorescent lights at $25^{\circ} \mathrm{C}$ temperatures for two months. Plants were carefully extracted from the media using forceps for measurement of root density and length $[13,15]$

\section{Results}

\section{In-vitro Growth Statistics}

According to the data in Table 1, P. fortuneii was found to have a higher average growth rate of 0.637 $\mathrm{cm}(\mathrm{SD}=0.22)$ per week in comparison to $0.355 \mathrm{~cm}$ $(\mathrm{SD}=0.12)$ per week growth rate of $P$. tomentosa. There was a significant difference in the growth rates of $P$. tomentos $a$ and $P$. fortuneii; $\mathrm{t}(6)=5.150, \mathrm{p}=$ 0.002 .

Both the line graphs represented peaks followed by a gradual decline in growth rate. In-vitro growth was found to peak during the $3^{\text {rd }}$ week for $P$. tomentosa $(0.543 \mathrm{~cm})$ and during the $4^{\text {th }}$ week for $P$. fortuneii $(0.727 \mathrm{~cm})$. In the following weeks, the growth receded slowly for the rest of the culture period. Within the $7^{\text {th }}$ week, plant height reached to an average of $5.188 \mathrm{~cm}(\mathrm{n}=16 ; \mathrm{SD}=0.98)$ for $P$. tomentosa and $7.197 \mathrm{~cm}(\mathrm{n}=16 ; \mathrm{SD}=1.68)$ for $P$. fortuneii.

\section{Rooting Optimization}

Sand rooting: Comparative study of root development between two species

Out of 64 explants, 35\% survived after 4 weeks of incubation in the polythene chamber. Among those, $55 \%$ were $P$. fortuneii samples and $45 \%$ were $P$. tomentosa samples.

As shown in Table 2, the average root length of $P$. tomentosa samples was estimated to be $3.72 \mathrm{~cm}$ $(\mathrm{n}=11 ; \mathrm{SD}=1.32)$ and the average root number was calculated to be $10.22(\mathrm{n}=11 ; \mathrm{SD}=5.64)$. For $P$. 
Table 1: Average height growth rate (in $\mathrm{cm} /$ week) of both species of plants for 7 weeks $(\mathrm{n}=16)$. The average in-vitro growth rate of $P$. fortuneii was found to be higher than that of $P$. tomentosa.

\begin{tabular}{ccccccccc}
\hline Species $\backslash$ Time & Week 1 & Week 2 & Week 3 & Week 4 & Week 5 & Week 6 & Week 7 & $\begin{array}{c}\text { Avg. Net } \\
\text { Growth Rate }\end{array}$ \\
\hline P. fortuneii & 0.186 & 0.547 & 0.789 & 0.908 & 0.72 & 0.65 & 0.662 & 0.637 \\
P. tomentosa & 0.142 & 0.331 & 0.543 & 0.397 & 0.359 & 0.301 & 0.411 & 0.355
\end{tabular}

fortuneii samples, the average root length was average root number was calculated to be 7.5 ( $n=12$; estimated to be $3.04 \mathrm{~cm}(\mathrm{n}=12 ; \mathrm{SD}=1.72)$ and the $\mathrm{SD}=7.38)$.

Table 2: Rooting Optimization with different concentrations of phytohormone NAA, performed in sand and invitro medium

\begin{tabular}{|c|c|c|c|c|c|}
\hline $\begin{array}{l}\text { Type of } \\
\text { Rooting }\end{array}$ & Species & $\begin{array}{c}\text { Hormone } \\
\text { Concentration } \\
(\mathrm{mg} / \mathrm{l})\end{array}$ & $\begin{array}{l}\text { Sample } \\
\text { Size (n) }\end{array}$ & Avg. Root Length (cm) & Avg. Root Number \\
\hline \multirow[t]{9}{*}{ SR } & \multirow[t]{4}{*}{ PT } & 0.5 & 3 & $3.33 \pm 1.44$ & $7.50 \pm 5.00$ \\
\hline & & 1 & 8 & $3.87 \pm 1.35$ & $11.25 \pm 5.82$ \\
\hline & & 1.5 & 0 & NA & NA \\
\hline & & Total & 11 & $3.72 \pm 1.32$ & $10.22 \pm 5.64$ \\
\hline & \multirow[t]{4}{*}{ PF } & 0.5 & 3 & $4 \pm 1.32$ & $5.83 \pm 2.88$ \\
\hline & & 1 & 5 & $3.4 \pm 2.16$ & $11.50 \pm 10.24$ \\
\hline & & 1.5 & 4 & $1.87 \pm 0.75$ & $3.75 \pm 2.50$ \\
\hline & & Total & 12 & $3.04 \pm 1.72$ & $7.50 \pm 7.38$ \\
\hline & \multicolumn{2}{|c|}{ Sum Total } & 23 & $3.36 \pm 1.55$ & $8.80 \pm 6.60$ \\
\hline \multirow[t]{9}{*}{ IVR } & \multirow[t]{4}{*}{ PT } & 0.5 & 1 & $2.60 \pm 0$ & $3.30 \pm 0$ \\
\hline & & 1 & 2 & $1.61 \pm 0.43$ & $1.37 \pm 0.53$ \\
\hline & & 1.5 & 2 & $2.13 \pm 0.38$ & $2.35 \pm 1.20$ \\
\hline & & Total & 5 & $1.96 \pm 0.44$ & $2.15 \pm 1.04$ \\
\hline & \multirow[t]{4}{*}{ PF } & 0.5 & 4 & $3.91 \pm 1.03$ & $2.92 \pm 1.40$ \\
\hline & & 1 & 3 & $2.36 \pm 0.11$ & $2.51 \pm 0.72$ \\
\hline & & 1.5 & 1 & $4.40 \pm 0$ & $4.80 \pm 0$ \\
\hline & & Total & 8 & $3.39 \pm 1.09$ & $3.00 \pm 1.25$ \\
\hline & \multicolumn{2}{|c|}{ Sum Total } & 13 & $2.84 \pm 1.13$ & $2.67 \pm 1.20$ \\
\hline
\end{tabular}

Abbreviations: SR - Sand Rooting, IVR - In-Vitro Rooting, PT - Paulownia tomentosa, PF - Paulownia fortuneii, NA - Not Applicable

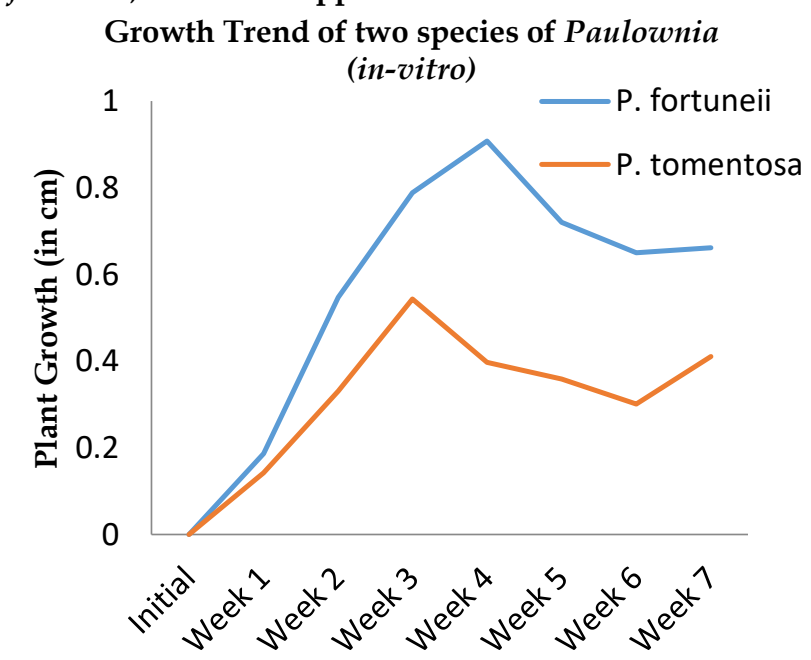

Figure 1: Line graph showing the growth trend of the two species in in-vitro conditions $(\mathbf{n}=16)$. Plants grown in MS medium with supplementation of $0.1 \mathrm{mg} / 1 \mathrm{NAA}$ and $1 \mathrm{mg} / 1$ BAP. Peaks in growth rate can be seen in Week 3 for $P$. tomentosa $(0.543 \mathrm{~cm} /$ week $)$ and in Week 4 for $P$. fortuneii $(0.908 \mathrm{~cm} /$ week $)$

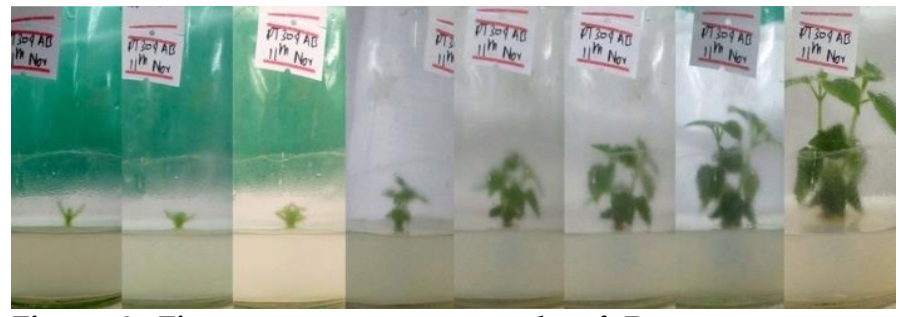

Figure 2: Figure represents a sample of $P$. tomentosa undergoing in-vitro growth for 7 weeks. The gradual invitro growth in plant height as well as biomass can be clearly visualized from this figure.

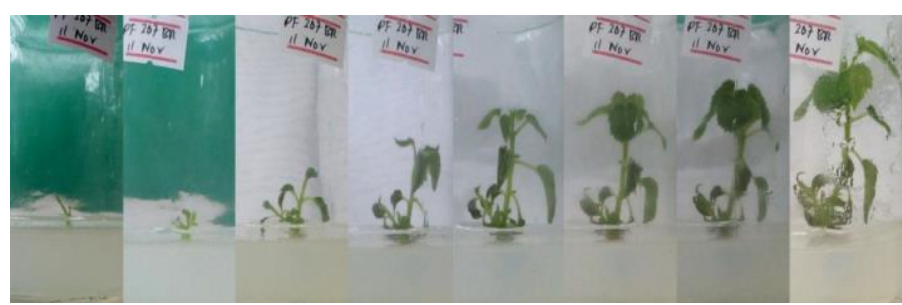

Figure 3: Figure represents a sample of $P$. fortuneii undergoing in-vitro growth for 7 weeks. The gradual invitro growth in plant height as well as biomass can be clearly visualized from this figure. 
Sand rooting: Comparative study of effect of varying concentrations of auxin (NAA) treatment in root development

As shown in Table 2, among the surviving samples, $26 \%$ had been treated with $0.5 \mathrm{mg} / 1 \mathrm{NAA}, 56 \%$ had been treated with $1 \mathrm{mg} / 1 \mathrm{NAA}$ and $17 \%$ had been treated with $1.5 \mathrm{mg} / 1 \mathrm{NAA}$.

Samples treated with $1 \mathrm{mg} / 1$ of NAA showed highest root density in both $P$. tomentosa and $P$. fortuneii. None of the $P$. tomentosa plants treated with $1.5 \mathrm{mg} / 1$ NAA survived the sand rooting, but both the average root length and root number from P. fortuneii plants treated with $1.5 \mathrm{mg} / 1$ were found to be low. P. fortuneii plants dipped in $0.5 \mathrm{mg} / 1$ NAA showed the highest average root length of $4 \mathrm{~cm}(\mathrm{n}=3 ; \mathrm{SD}=1.32)$.

\section{In-vitro rooting: Comparative study of} root development between two species

Callus formation was observed in all the in-vitro rooting samples. Root initiation was observed after 3 weeks of sub-culture. Out of 13 viable samples, $38 \%$ were $P$. tomentosa samples and $61 \%$ were $P$. fortuneii samples.

As shown in Table 2, the average root length of $P$. tomentosa samples were observed to be $1.96 \mathrm{~cm}$ $(\mathrm{n}=5 ; \mathrm{SD}=0.44)$ and the average root number was calculated to be $2.15(n=5 ; S D=1.04)$. For P. fortuneii samples, the average root length was observed to be $3.39 \mathrm{~cm}(\mathrm{n}=8 ; \mathrm{SD}=1.09)$ and the average root number was calculated to be $3(n=8 ; S D=1.25)$.

In-vitro rooting: Comparative study of effect of varying concentrations of auxin (NAA) treatment in root development

As shown in Table 2, among the viable samples, $38 \%$ had been treated with $0.5 \mathrm{mg} / 1 \mathrm{NAA}, 38 \%$ had been treated with $1 \mathrm{mg} / 1 \mathrm{NAA}$ and $23 \%$ had been treated with $1.5 \mathrm{mg} / 1 \mathrm{NAA}$.

Samples treated with $0.5 \mathrm{mg} / 1$ NAA showed the highest average root length and density for $P$. tomentosa, while samples treated with $1.5 \mathrm{mg} / 1$ showed the highest average root length and density for P. fortuneii.

\section{Comparison of root length and root number between in-vitro rooting samples and sand rooting samples}

As shown in Table 2, while comparing average root length and root number between different rooting techniques, sand rooting was clearly better suited for root development than in-vitro rooting technique.

In case of sand rooting samples, their average root length was estimated to be $3.36 \mathrm{~cm}(\mathrm{n}=23 ; \mathrm{SD}=1.55)$ and the average root number was calculated to be $8.80(\mathrm{n}=23 ; \mathrm{SD}=6.60)$. For in-vitro rooting samples, the average root length was estimated to be $2.84 \mathrm{~cm}$ $(n=13 ; S D=1.13)$ and the average root number was calculated to be $2.67(n=15 ; S D=1.20)$.

\section{Discussion}

Mass propagation of Paulownia plants by tissue culture is gaining popularity in Nepal. Due to this, many research works are being carried out on different species of Paulownia both in and outside Nepal.

$P$. fortuneii was found to have higher average growth rate among the two species. This result could be interpreted as $P$. fortuneii having a greater metabolic ability to utilize the energy and nutrients from MS medium than that of $P$. tomentosa.

Despite the lower average growth rate in in-vitro condition, $P$. tomentosa overcame its flaws by demonstrating superiority during sand rooting. $P$. tomentosa samples were found to have higher average root length as well as higher root density than that of $P$. fortuneii. Optimization test of hormone pre-treatment showed that the samples treated with 0.5 and $1 \mathrm{mg} / 1 \mathrm{NAA}$ had greater average root length than those treated with $1.5 \mathrm{mg} / \mathrm{l}$. Out of 10 P. tomentosa samples dipped in $1.5 \mathrm{mg} / 1 \mathrm{NAA}$, none of the samples survived the sand rooting process. $P$. fortuneii samples dipped in $1.5 \mathrm{mg} / 1$ NAA also resulted in shorter and sparser roots. It was also observed that samples treated with $1 \mathrm{mg} / 1$ NAA had higher average root density. These results suggest that concentrations of 0.5 and $1 \mathrm{mg} / 1$ are optimum for treatment before transfer to sand.

Callus formation was observed in in-vitro rooting samples which are probably induced by mechanical damage to the nodal cutting and presence of auxin (NAA) during the culture process. P. fortuneii demonstrated higher densities and lengths of roots in in-vitro rooting. This result also supports our interpretation that $P$. fortuneii may have a greater ability to utilize energy and nutrients from MS medium. Conversely, root length and density were found to be higher in in-vitro media having 
hormone concentration of $0.5 \mathrm{mg} / 1$ and $1.5 \mathrm{mg} / 1$. This inconsistency in the result may have stemmed from inadequate sample size, so further studies must be conducted.

While comparing the results from sand and in-vitro rooting techniques, we found sand rooting technique resulted in longer and denser roots. Due to the high availability of water and nutrients during in-vitro conditions, smaller and sparse roots may have been enough to sustain the plant whereas the scarcity of water and nutrients during sand rooting may have promoted higher root growth. A study performed by Rodrigues et al. in 1995 demonstrated a significant increase in root density during water deficit, which is similar to our findings [14-16].

\section{Conclusion}

In the comparison of in-vitro growth statistics of $P$. tomentosa and P. fortuneii, the latter was found to have higher average growth rate. Growth curves were found to peak at $3^{\text {rd }}$ and $4^{\text {th }}$ weeks respectively for the two species.

In the study to optimize rooting, $P$. tomentosa was found to have higher root length as well as root density during sand rooting, but $P$. fortuneii showed better root development in in-vitro conditions. Among the different concentrations of NAA, 0.5 and $1 \mathrm{mg} / 1$ were found to bear the best results during sand rooting. In case of in-vitro rooting, 0.5 and $1.5 \mathrm{mg} / 1$ concentrations of NAA were found to give better roots.

Comparison between the two rooting techniques showed that sand-rooting is the better method for root induction in case of Paulownia plants as both $P$. tomentosa and $P$. fortuneii demonstrated better results during sand rooting.

\section{References}

1. Rajbahak S, et al: Clonal Propagation of Paulownia tomentosa Steud. for Commercial Production. Bull. Dept. Pl. Res. 2014, 36:56-60.

2. Siebold and Zuccarini Fl: Paulownia. Flora of China 1998, 18:8-10.

3. Melhuish JH, Gentry CE and Beckjord, P R: Paulownia tomentosa Seedling growth at Differing Levels of pH, Nitrogen, and Phosphorous. J Environ Hort. 1990, 8:205-207.
4. Akyildiz MH and Kol HS: Some Technological Properties and Uses of Paulownia tomentosa Steud. wood. J Environmental Biology 2010, 31:351-355.

5. Zhu ZH, Chao CJ, Lu XY, Xiong YG: Paulownia in China: Cultivation and Utilization. Asian Network of Biological Sciences. Edi- A.N. Rao et al. 1986, 1-65.

6. Tang, RC, et al: Paulownia - A crop tree for wood products and reclamation of surface-mined land. South J Appl For. 1980, 4:19-24.

7. Yorgun S and Yildiz D: Slow pyrolysis of Paulownia wood: Effects of Pyrolysis Parameters on Product Yields and Bio-oil Characterization. J. Anal. Appl. Pyrolysis. 2015, 114:68-78.

8. Coombes AJ: The $\mathbf{A}$ to $\mathbf{Z}$ of Plant Names. USA Timber Press 2012, 312

9. Zima A, Hosek J, Treml J, Muselík J, Suchý, P et al: Antiradical and Cytoprotective Activities of Several C-Geranyl-substututed Flavonones from Paulownia tomentosa Fruit. Molecules. 2010 15:6035-6049.

10. Rajkarnikar KM and Rajbahak S: In-vitro Multiplication of Paulownia fortuneii (Seem.) Hemsl. through Seed Culture. Bull Dept Pl Res. 2015 37:63-65.

11. Kumar PP, Rao CD, Rajaseger G, Rao AN: Seed Surface Architecture and Random Amplified Polymorphic DNA Profiles of Paulownia fortunei, Paulownia tomentosa and their Hybrid. Annals of Botany 1999, 83:103-107.

12. Rajbhandary SB and Bajaj YPS: Rooting of in vitro produced shoots in nonsterile sand - An inexpensive and efficient technique for enmasse micropropagation. Biotechnology in Agriculture and Forestry 1991, 17:262-268.

13. Venkateswarlu B, Mukhopadhyay J, Sreenivasan E, Kumar VM: Micropropagation of Paulownia fortuneii through in vitro axillary shoot proliferation. Indian J Exp Biol 2001, 39:594-599.

14. Magar LB, Shrestha N, Khadka S, Joshi, J., Acharya, J., Gyanwali, G., Marasini, B., Rajbahak, S., \& Parajuli, N: Challenges and Opportunity of in vitro propagation of Paulownia tomentosa Steud for Commercial Production in Nepal. Int J Appl Sci Biotechnol 2016, 4:155-160.

15. Bergmann BA and Whetten R: In vitro rooting and early greenhouse growth of micropropagated Paulownia elongata shoots. New Forests 1997, 15:127138.

16. Rodrigues ML, Pacheco CMA and Chaves MM: Soilplant water relations, root distribution and biomass partitioning in Lupinus albus L. under drought conditions. J Exp Bot 1995, 46:947-956 